off at the same time, it would pass through the trouble, on its way to the surface, and be partly condensed in the cavities, and other cool places it came in contact with. It is highly probable that the other varieties of fossil wax may have been derived from a similar source.

In considering the inflammable and explosive substances existing in coal mines it is usual to limit the attention solely to the permanent gas given off, without adverting to the possibility of other substances of a volatile nature, being also emitted in the state of vapour. The occurrence of this variety of Ozocerite, in Urpeth Colliery, shows us that the light carburetted hydro. gen sometimes carries along with it other volatile substances, and there is strong reason for believing that the combustible portion of the atmosphere of our coal mines rarely, if ever, consists wholly of this light gas. To show the Proteus-like character of the compounds of carbon and hydrogen, in the ratio of atom to atom, and how little chemical analysis can avail di. rectly in determining the total absence of these substances, I subjoin a table, exhibiting the characteristic properties of the numerous bodies we are already acquainted with, in which the elements exist in this proportion.

\begin{tabular}{|c|c|c|c|c|c|c|c|}
\hline 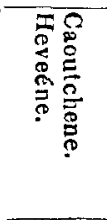 & 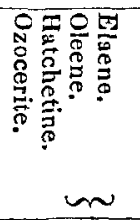 & 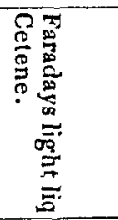 & 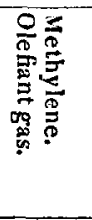 & 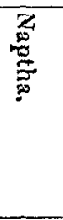 & $\begin{array}{l}0 \\
0 \\
0 \\
0 \\
0 \\
0\end{array}$ & 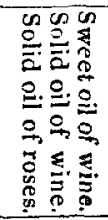 & \\
\hline 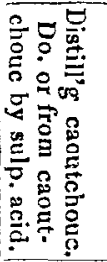 & 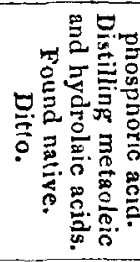 & 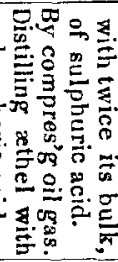 & 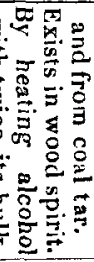 & 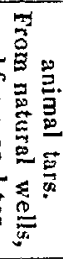 & $\begin{array}{l}7 \\
0 \\
3 \\
3 \\
\vdots \\
0 \\
0 \\
0 \\
0 \\
0 \\
0 \\
0 \\
0\end{array}$ & 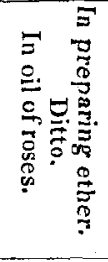 &  \\
\hline 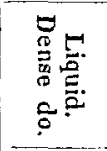 & 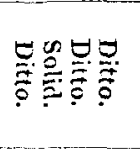 & 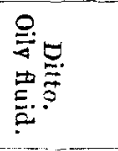 & 电 & . & & 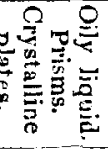 &  \\
\hline 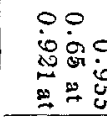 & 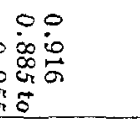 & 家 & 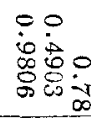 & $\begin{array}{l}\stackrel{0}{y} \\
\text { ov } \\
0 \\
0\end{array}$ &  & 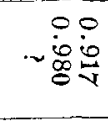 & 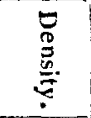 \\
\hline 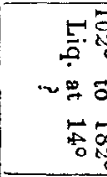 & 年 & $\underset{0}{\stackrel{5}{5}}$ & $\rightarrow$ & $\sim$ & $\begin{array}{l}- \\
0 \\
0 \\
\vdots \\
0\end{array}$ & 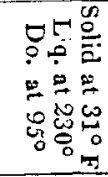 &  \\
\hline 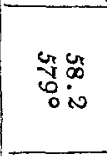 & $\begin{array}{l}0 \\
0 \\
0 \\
0 \\
0 \\
0 \\
0 \\
0 \\
0 \\
0\end{array}$ & 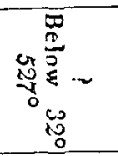 & $\sim$ & $\begin{array}{l}-7 \\
0 \\
0 \\
0 \\
0 \\
10 \\
0 \\
0.0\end{array}$ & $\sim$ & 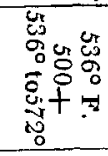 & 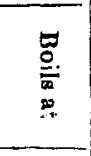 \\
\hline & 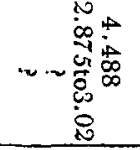 & 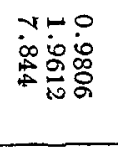 & $\stackrel{0}{\dot{8}}$ & 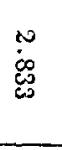 & $\sim$ & & 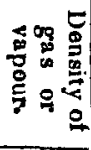 \\
\hline
\end{tabular}


A glance at the second column of this table shows that several of these substances are obtained from the products of the distillation of coal; and though it has not been demonstrated that any of them actually exist ready formed in the mass of the coal itself, yet the very low temperature at which some of them are given off lends to this opinion a considerable degree of probability. Richenbach states that bituminous coal by distillation with water, yields $1.320,000$ th of an $x$ thereal oil, which is identical with native naphtha; and he concludes that the uaphtha and petroleum springs of Persia. Intia, Italy, and South America, have their origin in the slow distilla. tion of large beds of coal, by the ordinary heat of the earth. The fossil wax of Moldavia and the hatchetine of England, are probably derived from vegetable matter by a like agency.

Naphtha is a comparatively dense fuid, requiring a temperature of upwards of $173^{\circ} \mathrm{Fahr}$. to boil it; and, therefore, unless present in large quantity, it will rarely escape from the coal so rapidly as alone to render the atmosphere combustible; but, suppose the very light liquid discovered in oil -gas to exist in the coal, it will at once escape as a highly inflammable gas, and materially injure the atmosphere. Because such substances have not hitherto been observed in the air of mines, we ought not hastily to conclude that they do not exist, really formed, in the great laboratory of nature. The difficulty of detecting them in a limited portion of gaseous matter will, probably, long present insuperable obstacles to the analytical chemist, while the more we learn of the carbo-hydrogens the more likely it appears that several of them should be occasionally present in the air which circulates through mines of bituminous coal.

The common fire damp requires, for its perfect combustion, ten times its bulk, the vapour of Faraday's light liquid thirty times, and that of naphtha forty-five times its bulk of common air. A very small portion of either of the latter, therefore, would render an atmosphere dangerous. The sudden outburst of a small reservoir would pollute a working previously considered safe, and give rise to an explosion where none was considered possible. In a district of country like the north of England, where rich bituminous coa! is so abundant, where mines are worked at the very verge of the inflammable state, and where the most serious accidents from explosions occasionally occur, it is of importance, I think, that the probable presence of such sub. stances, in the state of vapour, should be taken into account. Where the coal is richer than usual, and where troubles occur in which these compounds, as at Urpeth, may exist in a liquid or solid state, the rapid escape of combustible matter may be anticipated; while the probability of such escape affords a rational explanation of those sudden and unexpected emissions of gaseous matter which tiave occasionally been followed by consequen. ces so disastrous.**

An observation familiar to practical men in the English coal fields leads to the same conclusion. In mines where candles or open lamps are used, it is by the appearance of the flame that the miner judges of the purity of the atmosphere, and the presence of combustible matter. When little inflammable gas is mixed with the air, the flame carries over it a very short pale blue head, which increases in length as the quantity of the carbo-hydrogen increases, until the whole atmosphere becomes one explosive mixture.

* Another explanation had previously been giren by Mr. Hutton, in following up an idea originally suggested we believe by Dr. Paris; see L. and E. Phil. Mag. vol. ii. p. 303; and Parr's Life of Davy, p. 395. Both are probably true.-EnfT. 
But in different coal fields, the length of head, as it is called, which indicates an approach to the explosive state, is very different. In the Newcastle and Leeds coal fields $1 \frac{1}{2}$ inches indicate danger; in $S$. Wales 4 or 5 in. are not unusual. The colour of the head is also a criterion by which the miner judges; when blue, combustible matter is present, and an explosion is to be feared; if brown and muddy, carbonic acid is suspected, and the danger is less.

Though no parlicular conclusions can be drawn from these observations, yet the general result does force itself upon us, that the various compounds of carbon are at different times present in the attmosphere of coal mines in various quantities; and that sudden explosions may often be caused by the escape from cavities in the coal strata of other compounds than that usually called the fire damp, and to which all the mischief is usually attributed.

Durham, March, 1838.

Note. -I have just seen in the possession of Prof. Graham, of University College, a candle formed of a substance said to be found in considerable quantities in the coal mines near Linlithgow in Scolland. It resembles in every respect the Ozocerite candles of Moldavia. The substance is dull brown, and after fusion almost black, reflected and reddish brown by transmitted light; mass opake but translucent at the edges and in thin layers; is greasy to the touch (like Hatchetine, easily scratched by the nail, bas a conchoidal fracture, and when cold has no perceptible smell.

I may here mention also that the Middletonite described in a former paper, has since been met with in the mass of the coal in the Newcastle coal field. May not this substance be the resin of the trees of the carboniferous ara more or less changed.-A pril 16.

Lond. \& Edın. Philos. MIag.

\section{Electrical Induction.}

Dr. Faraday in his last series of "experimental researches in Electricity," (eleventh series) thus expresses his opinion of the actual condition and itmportance of this department of science.

"The science of electricity is in that state in which every part of it requires experimental investigation; not meraly for the discusery of new effects, but, what is just now of far more importance, the development of the means by which the old effects are produced, and the consequent more accurate determination of the first principles of action of this most extraordinary and universal power in nature:- and to those philosophers who pur. sue the inquiry zealously yet cautiously, combining experiment with analogy, suspicious of their pre-conceived notions, paying more respect to a fact than a theory, not too hasty to generalize, and, above all things, willing at every step to cross-examine their own opinions, both by reasoning and experiment, no branch of knowledge can afford so fine and ready a field for discovery as this. Such is most abundantly shown to be the case by the progress which electricity has made in the last thirty years : Chemistry and Magnetism have successively acknowledged its overruling influence; and it is probable that every effect depending upon the powers of inorganic matter, and perhaps most of those related to vegetabie and animal life, will ultimately be found subordinate to it."

The true theory of electrical action appears to be absolutely dependent on a knowledge of the nature of Induction. To this, therefore, he has directed, almost exclusively, his recent experimental researches.

"Amongst the actions of different kinds into which electricity has con$33^{*}$ 